\title{
Corneal power after photoablative surgery for intraocular lens calculation using Pentacam-AXL
}

\section{Poder corneal poscirugía fotoablativa para el cálculo de la lente intraocular aportado por el Pentacam-AXL}

\author{
Taimi Cárdenas-Díaz*, M. Teresa González-Hernández, and Michel Guerra-Almaguer \\ Instituto Cubano de Oftalmología Ramón Pando Ferrer, Havana city, Cuba
}

\begin{abstract}
Objective: To compare the intraocular lens power calculated with the total refractive corneal power (TRCP), the effective keratometric readings (EKR) provided by the Holladay Report of the Pentacam-AXL topographer and the true corneal power (True-K) used by the Barret True-K formula incorporated in the equipment, with the values obtained by the clinical history method (CHM) in patients with previous photoablative surgery for myopia correction. Method: A cross-sectional study was carried out in 99 eyes of 52 myopic patients after photoablative surgery in the Refractive Surgery Department of the Ramón Pando Ferrer Institute from November 2018 to November 2019. Demographic, refractive and biometric characteristics were evaluated, including corneal powers obtained by the Pentacam-AXL. We compared corneal power and the intraocular lens power calculation. Results: Mean age was $25.71 \pm 4.46$ years, there was a female predominance $(67.3 \%)$ and the spherical equivalent was $-0.06 \pm 0.34$ diopters. There were only significant differences in mean keratometry $(p=0.02)$ and intraocular lens power calculated using keratometry $(p<0.01)$ compared with that calculated using the MRM; not so with EKR, TRCP and True-K. Conclusions: The effective keratometric readings provided by the Holladay Report module of the Pentacam, the total corneal refractive power and the true corneal power used by the Barret True-K formula, do not differ from the corneal power obtained by the MRM in eyes with previous photoablative surgery for myopia correction, so they can be used for intraocular lens calculation.
\end{abstract}

Keywords: Corneal power. Photoablative surgery. Intraocular lens.

\section{Resumen}

Objetivo: Comparar el poder de la lente intraocular calculada con la potencia refractiva total corneal (TRCP), las lecturas queratométricas efectivas (EKR) aportadas por el Holladay Report del topógrafo Pentacam-AXL y el poder corneal real (True-K) utilizado por la fórmula de Barret True-K incorporada en el propio equipo, con los valores obtenidos por el método de historia clínica (MHC) en pacientes con cirugía fotoablativa previa para corregir la miopía. Método: Se realizó un estudio transversal en 99 ojos de 52 pacientes miopes poscirugía fotoablativa en el Servicio de Cirugía Refractiva del Instituto Ramón Pando Ferrer, de noviembre de 2018 a noviembre de 2019. Se estudiaron características demográficas, refractivas y biométricas que incluyeron poderes corneales aportados por el Pentacam-AXL. Se compararon el poder corneal y el poder de la lente intraocular calculada. Resultados: La edad media fue de $25.71 \pm 4.46$, hubo predominio femenino (67.3\%), y el equivalente esférico fue de $-0,06 \pm 0,34$ dioptrías. Solo hubo diferencias significativas en la queratometría media $(p=0.02)$

Correspondence:

${ }^{*}$ C. Taimi Cárdenas-Díaz

Canal 3116, entre 11 y 12, reparto Antoni Maceo Fecha de recepción: 11-05-2021

C.P. 10400 , Cerro, La Habana, Cuba

E-mail: taimicar@infomed.sld.cu

2604-1731/๑ 2021 Sociedad Mexicana de Oftalmología. Published by Permanyer. This is an open access article under the CC BY-NC-ND license (http://creativecommons.org/licenses/by-nc-nd/4.0/).
Fecha de aceptación: 07-07-2021
Available online: 05-11-2021 Rev Mex Oftalmol (Eng). 2021;95(6):237-243

www.rmo.com.mx 
y el poder de la lente calculado con esta $(p<0.01)$ al compararlo con el obtenido por el MHC; no así con la EKR, la TRCP y el True-K. Conclusiones: Las lecturas queratométricas efectivas que aporta el módulo Holladay Report del Pentacam, la potencia refractiva total corneal y el poder corneal real utilizado por la fórmula de Barret True-K no difieren del poder corneal obtenido por el MHC en ojos con cirugía fotoablativa previa para corregir la miopía, por lo cual pueden emplearse en el cálculo de la lente intraocular.

Palabras clave: Poder corneal. Cirugía fotoablativa. Lente intraocular.

\section{Introduction}

It is increasingly common to schedule cataract surgeries in myopic patients who have previously undergone corneal refractive surgery (CRS), which modifies the central cornea, so that conventional measurement methods overestimate corneal power. Current literature suggests that this overestimation is $14-25 \%$ after refractive surgery'.

During the last 17 years, more than 30 formulas or methods have been developed for calculating intraocular lens (IOL) power, which can be grouped according to the availability of data: 1) when keratometry or refractive changes are available (Seitz/Speicher method), 2) when the keratometric index can be recalculated (Savini's method, Masket's formula, Barrett's True-K formula, Latkany's regression formula, Awwad formulas (six) and medical records method [MRM]) and 3) when keratometry and refractive changes are not available (PHL and Shammas-PL formulas, Maloney method, Haigis-L formula, nonhistorical Barrett True-K formula and Gaussian optics formula) 2,3.

The MRM has been well known since its introduction by Holladay in 1989 and Hoffer in 1995. Although it has been considered the gold standard for years, studies have indicated that it is less accurate than newer methods. Its accuracy depends on the availability of preoperative data, and this is not always possible. Patients change healthcare centers, in some cases the previous keratometries are not recorded and other times the ophthalmologist who attends them is not the one who operates on the patient, and thus only the current refractive state of the patient is available. Furthermore, it has poor reliability when the data is imprecise ${ }^{2-4}$.

The need to obtain the correct corneal power after photoablative surgery to use it for IOL calculation is of increasing interest, since the number of patients with cataract and CRS history is increasing every day. The ideal for the surgeon is to have a device that measures corneal power directly and correctly, without making calculations or inferences. The Scheimpflug Pentacam-AXL $\mathrm{L}^{5-10}$ topographer is a very useful tool in estimating corneal power in patients with previous refractive surgery, since it has applications to carry out this measurement, such as total corneal refractive power (TRCP), incorporated into its software, the true corneal power (True-K) used in the Barret True- $\mathrm{K}^{11,12}$ formula and the Holladay Report program ${ }^{13}$. In the studies carried out at the Instituto Cubano de Oftalmología Ramón Pando Ferrer (ICORPF) ${ }^{3,14,15}$ to compare the values provided by the Pentacam topographer with those of the MRM in patients with CRS, a greater correlation was observed with effective keratometric readings (EKR, Equivalent Keratometry Readings) at 3 and $4 \mathrm{~mm}$ in myopic patients, but it is not known with TRCP and True-K. On the other hand, in the ICORPF itself, the Barret True-K formula incorporated into the Pentacam-AXL was useful for IOL calculation in patients with cataract and previous $\mathrm{CRS}^{16}$.

The present study was carried out with the objective of comparing the power of the IOL calculated with the TRCP, the EKR provided by the Holladay Report of the Pentacam-AXL and the True-K used by the Barret True-K formula incorporated in the topographer, with the values obtained by the MRM in patients with previous photoablative surgery to correct myopia.

\section{Methods}

This is a cross-sectional study in patients with previous photoablative surgery to correct myopia performed by the same surgeon in the refractive surgery department of the ICORPF, from November 2018 to November 2019. Patients with at least 3 months after CRS by excimer laser were included and those with previous ocular conditions and other ocular surgeries were excluded.

The demographic (sex and age) and refractive characteristics such as the spherical equivalent and biometric characteristics were studied, including the axial length and anterior chamber depth, in addition to the corneal powers provided by the Pentacam-AXL ${ }^{5-10}$, for example, mean keratometry $(\mathrm{Km})$ measured within the central $3.00 \mathrm{~mm}$, as well as TRCP at $4.00 \mathrm{~mm}$ that considers the true optical conditions of the cornea and 
the EKR of the Holladay Report module at $3.00 \mathrm{~mm}$, $4.00 \mathrm{~mm}$ and $4,50 \mathrm{~mm}$, which are effective after photoablative $\mathrm{CRS}^{13-15}$. The corneal power used by the Pentacam-AXL to calculate the IOL was also analyzed with the Barret formula ${ }^{11,12,16}$, named True-K, and that calculated by the $\mathrm{MRM}^{2-4,14,15}$, which uses the formula $\mathrm{K}=\mathrm{Kpre}+\mathrm{Rpre}-\mathrm{Rpo}$, where Kpre is the preoperative corneal power, Rpre is the preoperative refraction and Rpo is the postoperative refraction. This method, as had previously been stated, is still considered by many authors ${ }^{2-4,14,15}$ the standard method to obtain corneal power after CRS, which is why it was used as a reference in this study for comparisons.

The power of the IOL was calculated with each of these corneal powers. To avoid the prediction error of the effective lens position (ELP), the fourth generation Haigis formula was used, which does not use keratometry as a predictor of ELP, to validate the result ${ }^{17}$. In the case of the EKR of the Holladay Report, the recommended formula is the Holladay II, but it is not available in the Pentacam-AXL of the ICORPF, and although it is in the IOL Master 700, the latter does not allow to enter the values of the EKR, and that is why the Haigis is also used. In the case of the Barret formula that is incorporated in the Pentacam-AXL, in the same way it did not allow the corneal power to be modified and hence the intraocular lens power provided and the corneal power it uses (True-K) were analyzed.

Statistical analysis was performed with a paired t-test, with a significance of $95 \%$. A difference with a $p$ value $<0.05$ was considered statistically significant.

The study fulfilled the provisions of the National Health System and provided for in Law No. 41 on Public Health, in correspondence with the Declaration of Helsinki ${ }^{18}$. In addition, it was approved by the ethics and scientific committee of the authors' institution, and all participants signed the informed consent.

\section{Results}

Ninety-nine eyes of 52 patients with previous photoablative surgery to correct myopia were included, with a mean time between CRS and the Pentacam AXL examination of $6.30 \pm 3.56$ months (range: $3-12$ months). All patients were treated using the LASEK (Laser Assisted Sub-Epithelial Keratomileusis) surface technique.

Table 1 summarizes the demographic, refractive, and biometric characteristics of the patients. There was a predominance of the female sex, representing $67.3 \%$ of all patients. Average age was $25.71 \pm 4.46$ years (range:
Table 1. Demographic, refractive and biometric characteristics

\begin{tabular}{|l|l|c|}
$\begin{array}{l}\text { Sex } \\
(\mathrm{N}=52)\end{array}$ & Female, $\mathrm{n}(\%)$ & $35(67.3)$ \\
\hline Age (years) & Male, $\mathrm{n}(\%)$ & $17(32.7)$ \\
\hline Spherical equivalent (diopters) & $\begin{array}{l}\text { Mean } \pm \mathrm{SD} \\
\text { (min-max) }\end{array}$ & $\begin{array}{c}25.71 \pm 4.46 \\
(21-44)\end{array}$ \\
\hline Axial length $(\mathrm{mm})$ & $\mathrm{SD}$ & $\begin{array}{c}-0.06 \pm 0.34 \\
(-1.75-0.50)\end{array}$ \\
\hline Anterior chamber depth $(\mathrm{mm})$ & Mean $\pm \mathrm{SD}$ & $3.19 \pm 0.25$ \\
\hline
\end{tabular}

SD: standard deviation.

$21-44$ years). The average refractive error was $-0.06 \pm$ 0.34 diopters (D), achieving the objective of surgery. Mean axial length was $24.26 \pm 0.90 \mathrm{~mm}$ and that of the anterior chamber width was $3.19 \pm 0.26 \mathrm{~mm}$ provided by the Pentacam AXL.

Table 2 shows the corneal power obtained using the MRM and the Pentacam AXL topographer. The average corneal power with the MRM was $41.36 \pm 1.81 \mathrm{D}$, while the $\mathrm{Km}$ taken from the Pentacam AXL was 41.71 $\pm 1.61 \mathrm{D}$. The EKRs were analyzed, which at $3.0 \mathrm{~mm}$ were $41.22 \pm 1.76 \mathrm{D}$, at $4.0 \mathrm{~mm}$ were $41.21 \pm 1.73 \mathrm{D}$ and at $4.5 \mathrm{~mm}$ were $41.22 \pm 1.71 \mathrm{D}$. TRCP was 41.22 $\pm 1.73 \mathrm{D}$ at $4.0 \mathrm{~mm}$, while the True- $\mathrm{K}$ was $41.22 \pm 1.72$ $D$. In addition, we analyzed the differences between the corneal power provided by the Pentacam AXL topographer and that obtained with the MRM, with significant differences in mean keratometry of $0.35 \pm 0.75 \mathrm{D}$ $(p=0.02)$. EKR at 3.0, 4.0 and $4.5 \mathrm{~mm}$ had no important variations; there was a mean difference of $-0.14 \pm$ $0.71 \mathrm{D}(\mathrm{p}=0.05)$ at 3.0 and $4.0 \mathrm{~mm}$, and of $-0.13 \pm$ $0.67 \mathrm{D}(p=0.05)$ at $4.5 \mathrm{~mm}$. There were also no significant changes in TRCP at $4.1 \mathrm{~mm}$, with $-0.13 \pm 0.77$ $D(p=0.09)$, nor in the True-K, which was $-0.14 \pm 0.73$ $D(p=0.06)$.

Table 3 shows the IOL power calculated with the different corneal power values obtained using the Pentacam AXL topographer and the MRM, as well as the difference between them. The mean power of the IOL calculated by MRM was $21.37 \pm 1.70 \mathrm{D}$, while per $\mathrm{Km}$ it was $20.11 \pm 2.75 \mathrm{D}$, with a significant difference of -1.25 \pm 2.57 ( $p$ <0.01). On the other hand, IOL power using the EKRs at 3.0, 4.0 and $4.5 \mathrm{~mm}$ were $21.56 \pm 1.51 \mathrm{D}$, $21.56 \pm 1.54 \mathrm{D}$ and $21.55 \pm 1.56 \mathrm{D}$, respectively, without statistically significant differences $(p=0.05)$. Similarly, there were no significant differences ( $p>0.05$ ) in IOL 
Table 2. Corneal power obtained by the medical records method and by the Pentacam AXL topographer

\begin{tabular}{|l|c|c|c|}
\hline Corneal power (D) & Mean \pm SD & Difference \pm SD & p* \\
\hline MRM & $41.36 \pm 1.81$ & - & - \\
\hline Km & $41.71 \pm 1.61$ & $0.35 \pm 0.75$ & 0.02 \\
\hline EKR at $3.0 \mathrm{~mm}$ & $41.22 \pm 1.76$ & $-0.14 \pm 0.71$ & 0.05 \\
\hline EKR at $4.0 \mathrm{~mm}$ & $41.21 \pm 1.73$ & $-0.14 \pm 0.71$ & 0.05 \\
\hline EKR at $4.5 \mathrm{~mm}$ & $41.22 \pm 1.71$ & $-0.13 \pm 0.67$ & 0.05 \\
\hline TRCP at $4.0 \mathrm{~mm}$ & $41.22 \pm 1.73$ & $-0.13 \pm 0.77$ & 0.09 \\
\hline True $K$ & $41.22 \pm 1.72$ & $-0.14 \pm 0.73$ & 0.06 \\
\hline
\end{tabular}

D: diopters; SD: standard deviation; EKR: effective keratometric readings; $\mathrm{Km}$ : mean keratometry; MRM: medical records method; TRCP: total refractive corneal power; True K: real corneal power.

*Paired t-test.

Table 3. Corneal power obtained by the medical records method and by the Pentacam AXL topographer

\begin{tabular}{|l|c|c|c|}
\hline Corneal power (D) & Mean \pm SD & Difference \pm SD & $p^{*}$ \\
\hline MRM & $21.37 \pm 1.70$ & - & - \\
\hline Km & $20.11 \pm 2.75$ & $-1.25 \pm 2.57$ & $<0.01$ \\
\hline EKR at $3.0 \mathrm{~mm}$ & $21.56 \pm 1.51$ & $0.19 \pm 0.96$ & 0.05 \\
\hline EKR at $4.0 \mathrm{~mm}$ & $21.56 \pm 1.54$ & $0.19 \pm 0.96$ & 0.05 \\
\hline EKR at $4.5 \mathrm{~mm}$ & $21.55 \pm 1.56$ & $0.18 \pm 0.90$ & 0.05 \\
\hline TRCP at $4.0 \mathrm{~mm}$ & $21.54 \pm 1.66$ & $0.21 \pm 1.01$ & 0.09 \\
\hline True $K$ & $21.52 \pm 1.63$ & $0.15 \pm 1.00$ & 0.14 \\
\hline
\end{tabular}

D: diopters; SD: standard deviation; EKR: effective keratometric readings; Km: mean keratometry; MRM: medical records method; TRCP: total refractive corneal power; True K: true corneal power.

*Paired t-test.

power calculated by TRCP at $4.0 \mathrm{~mm}(21.54 \pm 1.66 \mathrm{D})$ and with the true corneal power $(21.52 \pm 1.63 \mathrm{D})$.

\section{Discussion}

With the introduction and development of refractive surgery in Cuba at the beginning of the century, thousands of patients have been operated on, which has allowed us to establish our own criteria and regulations. In the present study, patients with at least 3 months from CRS were included, since this is the moment when most authors agree that refractive stability is reached ${ }^{17,19}$. LASEK was performed on all patients, coinciding with the study by Pérez Range ${ }^{17}$, in which there was a predominance of the use of LASEK over LASIK (Laser Assisted in Situ Keratomileusis). In other studies, such as that of Cabrera, et al. ${ }^{20}$, LASEK is also preferred using mitomycin $\mathrm{C}$, which has been shown to be as reliable as LASIK for the correction of ametropia. Rojas and González ${ }^{21}$, in an in vivo corneal morphometric evaluation using confocal microscopy, showed that LASEK has a lower impact on corneal homeostasis in terms of less loss of keratocytes, greater preservation of the residual corneal bed and better recovery of the sub-basal nerve plexus one year after surgery. However, other authors advocate the LASIK technique $^{22}$. As both offer advantages and disadvantages, this must be discussed between the surgeon and the patient to make a decision, based on an objectively established agreement; they allow a very similar visual quality but LASEK provides greater safety regarding the development of postsurgical ectasias, offering more stable corneas, as well as a superior quality of life when mitomycin $\mathrm{C}$ is used (which prevents haze), since it is very important for patients to recognize themselves as fully recovered individuals, without limitations for their social life, since they do not have to worry about corneal flap care, as with LASIK.

In our studym there was female predominance. In the study carried out by Kuo, et al. ${ }^{23}$ in order to identify the characteristics of the patients requesting CRS, the researchers reported that this procedure is mainly sought after by young people and women, in accordance with the investigations of Cumberland, et al. ${ }^{24}$ in the UK and Hashemi, et al. ${ }^{25}$ in Iran. This phenomenon can be explained in part by the greater aesthetic desire in women, and may be a reason that explains the prevalence observed in our study.

Regarding age and refractive error, the results of this work are consistent with the protocol for refractive surgery in force at the ICORPF, since it is for people over 21 years of age with refractive stability and without an upper age limit, with a clear lens and who meet the criteria for laser refractive surgery ${ }^{26}$.

The process for calculating IOL power should be modified when practiced on an eye with previous CRS, since there are two sources of error: the incorrect prediction of ELP by the formula and the erroneous determination of corneal power by keratometry; correcting these two factors will allow a correct calculation to be made in these eyes. Most of the formulas for IOL calculation are based on the position of the lens relative to the cornea, that is, on the ELP, to increase accuracy $^{1-4}$.

The total dioptric power of the cornea is the sum of the power of the anterior (convex lens) and posterior (concave lens) surfaces. After photoablative surgery 
there is a change in the curvature of the anterior surface (it flattens after myopia surgery and curves after hyperopia surgery), while the posterior corneal curvature does not change (or in any case the change is minimal). This alteration in the ratio on which the standard keratometric index value (1.3375) is based, leads to an overestimation of the total corneal power by the keratometer. Other factors involved in this error are the greater central sphericity in the cornea, the change in the refractive index of the corneal stroma, and the more peripheral measurement, since the aims are projected more peripherally on a flattened cornea. Traditional keratometry and keratometry simulated by corneal topography estimate corneal power by measuring the central $3.2 \mathrm{~mm}$ of the anterior surface. For a normal prolate cornea this assumption is adequate, but after refractive surgery the relationship is altered ${ }^{1-4}$.

In this study, the Km was the one that showed significant differences, which is justified by being the total dioptric power "estimated" from the anterior surface of the cornea, in a study area of approximately 3 central $\mathrm{mm}$ and with the use of the reference keratometric index 1.3375; hence instruments that measure both the anterior and posterior surfaces, such as the Pentacam, can reduce this error in the determination of total corneal power.

The Pentacam offers the EKRs, values obtained in the module named by Dr. Jack Holladay as Holladay Report, designed to take into account the refractive effect (Snell's law of refraction) and the effect of the posterior surface of the cornea. With this map, the 1.3375 index error creates a sagittal map that is added to it by compensating the loads, which can be similar to the result of the TRCP map. The TRCP provides the new Pentacam-AXL with the total data of the cornea, in a study area of $4 \mathrm{~mm}$ (effective pupillary area), considering the true refractive indices (air $=1$, cornea $=1.376$ and aqueous $=1.336$ ) and the "true" total dioptric power of the cornea, since it considers the true optical conditions of the cornea, taking into account the anterior and posterior surfaces with their correct refractive indices, in addition to pachymetry and central and peripheral corneal aberrations. Both EKR and TRCP make Pentacam ideal in patients with previous $\mathrm{CRS}^{3-15]}$.

In this work, there were significant differences in $\mathrm{Km}$ with the power calculated by the MRM, not the EKR at 3.0, 4.0 and $4.5 \mathrm{~mm}$ or the TRCP at $4.0 \mathrm{~mm}$ provided by the Pentacam-AXL, which were similar, coinciding with previous publications such as that of Karunaratne ${ }^{13}$, who compared the EKR of the Pentacam with the Km.
In one study, Shajari, et al. ${ }^{10}$ compared the total keratometry of the IOL Master 700 with the simulated K, the TCRP and the true net power of the Pentacam-AXL in 93 eyes of 93 patients, and concluded that the total keratometry of the IOL 700 is not interchangeable with the TCRP, although this is a recently introduced measurement and therefore more studies are necessary, especially due to its value in the calculation of toric IOLs.

The EKRs at 3.0, 4.0 and $4.5 \mathrm{~mm}$ calculated in this study using the Holladay Report program do not show differences with the mean keratometry calculated by the MRM, similar to other investigations carried out at the ICORPF. Cuan, et al. ${ }^{14}$ observed a higher correlation with the EKR at $3 \mathrm{~mm}$. It is necessary to clarify that in their research they only compared with the MRM and were myopic patients treated with excimer laser. Cárdenas, et al. ${ }^{27}$ performed a comparison of the values provided by the Pentacam and the Maloney method in the same group of patients, and obtained the smallest differences in the EKR at 3.0 and $4.0 \mathrm{~mm}$. In contrast, Pérez, et al. ${ }^{28}$, in a study with the objective of correlating the keratometric values obtained by the Holladay Report program of the Pentacam and by the Maloney method, concluded that all the variables show a statistically significant positive correlation with the values obtained by the Maloney method, but the highest correlation values corresponded to the EKR at 4.0 and $4.5 \mathrm{~mm}$, which indicated its closest approximation to that calculated by the Maloney formula. It is important to note that this study was carried out in eyes operated with radial keratotomy and a diagnosis of cataract.

Viteri ${ }^{29}$ states that, depending on the ablation profile, some surgeons prefer the EKR at 2 or $3 \mathrm{~mm}$, and in his opinion additional efforts must be made to determine the optimal area of the EKR for specific cases. In other studies, the authors found the greatest similarity to the MRM keratometric values in corneal power provided by the EKRs of the Holladay Report program, within a series of keratometric measurements performed by the Pentacam topographer in patients with CRS with an excimer laser ${ }^{30,31}$.

Another aspect studied was the difference with True-K, the corneal power used by the Pentacam-AXL for IOL calculation with the Barret True-K formula, in whose determination changes after refractive surgery are taken into account to calculate the preoperative keratometry and predicting the contribution of the posterior cornea. The mathematical formula for the Barrett True-K method has not been published. It is known that 
the keratometric index is modified and that it uses the Barrett Universal II and Double K formulas; It is used in patients with a history of refractive surgery and in eyes of any size. Several studies support its refractive results and consider it one of the best options in patients with a history of refractive surgery ${ }^{12,13,16}$. In this work there were no significant differences with True-K.

Wang, et al. ${ }^{32}$ determined the average values of the difference between standard total keratometry and that determined by topography, and observed that in myopic eyes, which generally tend to present a greater axial length, the values of the difference tended to be smaller than those observed in the hyperopic patients studied by them (eyes with shorter axial length).

Regarding IOL calculation by the different methods, we did not find significant differences between the use of corneal power calculated with the MRM and the different measurements provided by the Pentacam (EKR at 3.0, 4.0 and $4.5 \mathrm{~mm}$, TRCP and True-K); However, there was a significant difference in the power of the $\mathrm{IOL}$ calculated with $\mathrm{Km}$, not only statistically, but also from a clinical point of view, where one diopter of lens error can be equivalent to three diopters in refraction.

In an article published by Pérez, et al. ${ }^{28}$ with the aim of comparing the visual results of patients with CRS, cataract surgery and IOL implantation, calculated by the Maloney method and by Pentacam, it was observed that visual results were favorable both in patients in whom the Maloney method was used and in those in which the Pentacam was used to obtain corneal power for IOL calculation. However, it is important to note that emmetropia was achieved in a higher percentage in the group in which the EKR was used $(50 \%)$ compared to the one that used the $\mathrm{K}$ calculated by Maloney $(43.48 \%)$, so it is concluded that both methods provide favorable visual results, but calculating the IOL power with the EKRs provided by the Pentacam's Holladay Report offers better visual results for patients with a history of CRS. Similarly, other studies have concluded that the Pentacam topographer, through the Holladay Report program, provides corneal powers that can be used for IOL estimation in myopic or hyperopic patients with prior laser refractive surgery ${ }^{12,17}$.

The Barrett True- $\mathrm{K}$ formula is useful for IOL calculation in patients with previous CRS. Obtaining accurate refractive results makes it one of the best options in these patients ${ }^{12,13}$. On the other hand, in the ICORPF, the Barret True-K formula incorporated into the Pentacam-AXL was useful for calculating IOL power in patients with cataract and previous $\mathrm{CRS}^{16}$.

\section{Conclusions}

The Pentacam, through the Holladay Report Program, provides corneal powers that can be used for IOL power calculation in myopic eyes that have had previous excimer laser surgery, since the EKRs provided by the Holladay Report of the Pentacam, as well as the TRCP and the True- $\mathrm{K}$ used by the Barret True- $\mathrm{K}$ formula, do not differ from the corneal power obtained by the MRM in eyes with previous laser refractive surgery to correct myopia; not so the $\mathrm{Km}$, which does differ.

\section{Funding}

The authors declare that no funding was obtained for this research.

\section{Conflicts of interest}

The authors have no conflict of interest to report

\section{Ethical disclosures}

Protection of human and animal subjects. The authors declare that no experiments were performed on humans or animals for this study.

Confidentiality of data. The authors declare that they have followed the protocols of their Institution on the publication of patient data.

Right to privacy and informed consent. The authors have obtained the written informed consent of the patients or subjects mentioned in the article. The corresponding author is in possession of this document.

\section{References}

1. Galvis V, Tello A, Jaramillo LC, Castillo AM, Pareja LA, Camacho PA. Cambios corneales producidos por la cirugía refractiva con excimer láser: revisión de tema. MÉD UIS. 2017;30:99-105.

2. Savini G, Hoffer KJ. Intraocular lens power calculation in eyes with previous corneal refractive surgery. Eye Vis (Lond). 2018;5:18-27.

3. Cárdenas T. Poder corneal postcirugía fotoablativa para el cálculo del lente intraocular. [Tesis de Doctorado.] La Habana: Universidad de Ciencias Médicas de La Habana; 2015.

4. Cárdenas T, Guerra M, Hernández I, Cruz D, Montero E, Hernández R. Principios para el cálculo de la lente intraocular tras cirugía refractiva corneal. Rev Cub Oftalmol. 2016;29(1).

5. Cho K, Lim DH, Yang C, Chung ES, Chung TY Comparison of intraocular lens power calculation methods following myopic laser refractive surgery: new options using a rotating Scheimpflug camera. J Ophthalmol. 2018;32:497-505.

6. Kang BS, Han JM, On JY, Kim MK, Wee WR. Intraocular lens power calculation after refractive surgery: a comparative analysis of accuracy and predictability. Korean J Ophthalmol. 2017;31:479-88.

7. Cho K, Lim DH, Yoo YS, Chung TY. New method for intraocular lens power calculation using a rotating Scheimpflug camera in eyes with corneal refractive surgery. BMC Ophthalmol. 2020;10:8992.

8. Pereira JMM, Neves A, Alfaiate $P$, Santos M, Aragao $H$, Sousa JC. Lenstar $\AA$ LS 900 vs Pentacam $\AA$-AXL: comparative study of ocular biometric measurements and intraocular lens power calculation. Eur J Ophthalmol. 2018;28:645-51. 
9. Haddad JS, Barnwell E, Rocha KM, Ambrosio R Jr, Waring Iv GO. Comparison of biometry measurements using standard partial coherence in terferometry versus new Scheimpflug tomography with integrated axial length capability. J Clin Ophthalmol. 2020;14:353-8.

10. Shajari M, Sonntag R, Ramsauer M, Kreutzer T, Vounotrypidis E, Ko hnen $T$, et al. Evaluation of total corneal power measurements with a new optical biometer. J Cataract Refract Surg. 2020;46:675-81.

11. Abulafia A, Hill WE, Koch DD, Wang L, Barrett GD. Accuracy of the Barrett True-K formula for intraocular lens power prediction after laser in situ keratomileusis or photorefractive keratectomy for myopia. J Cataract Refract Surg. 2016;42:363-9.

12. Zhu W, Zhang FJ, Li Y, Song YZ. Stability of the Barrett True-K formula for intraocular lens power calculation after SMILE in Chinese myopic eyes. Int J Ophthalmol. 2020;13:560-6.

13. Karunaratne $\mathrm{N}$. Comparison of the Pentacam equivalent keratometry reading and IOL Master keratometry measurement in intraocular powe calculations. Clin Exp Ophthalmol. 2013;41:825-34.

14. Cuan Y, Pérez E, Montero E, Santiesteban I, Ortega L, Cárdenas T. Utilidad del topógrafo Pentacam para medir el poder corneal después de cirugía refractiva con excímer láser. Rev Cub Oftalmol. 2010;23 (Supl 1):513-21.

15. Cárdenas T, Guerra M, Pérez EC, Cuan Y, Hernández I. Cirugía refractiva láser previa y cálculo del lente intraocular en miopes. Rev Cub Oftalmol. 2017;30(2).

16. Cangrejo Forero El. Resultados del cálculo de lente en operados de catarata y cirugía refractiva: fórmula Barrett True K. [Tesis.] La Habana: Universidad de Ciencias Médicas de La Habana; 2020.

17. Pérez Rangel Y. Cálculo del lente intraocular en pacientes con cirugía refractiva láser previa. [Tesis.] La Habana: Universidad de Ciencias Médicas de La Habana; 2019.

18. Di Ruggiero M. Declaración de Helsinki, principios y valores bioéticos en juego en la investigación médica con seres humanos. Revista Colombiana de Bioética. 2011;6:125-44

19. Rey DV, Moreno Montoya J. Resultado visual a los 3 meses de cirugía LASEK. Rev Mex Oftalm. 2017;91:247-53.

20. Cabrera Martínez A, Cabrera Martínez JA, Tirado Martínez OM. Resultados refractivos en pacientes operados por LASIK versus LASEK con mitomicina C. Rev Cub Oftalmol. 2009;36(7).
21. Rojas Álvarez E, González Sotero J. LASIK vs. LASEK desde la perspectiva morfométrica corneal in vivo. Rev Mex Oftalm. 2013;87:145-57.

22. Sierra PB, Hardten DC. LASIK. En: Yanoff M, Duker JS, editores. Oftalmología. 5. ${ }^{a}$ ed. Barcelona: Elsevier; 2019. p. 95-105.

23. Kuo I, Lee B, Wang J. Outcomes of refractive surgery consultations at an academic center: characteristics associated with proceeding (or not proceeding) with surgery. J Ophthalmol. 2020;2020:4354085.

24. Cumberland PM, Chianca A, Rahi JS. Laser refractive surgery in the UK Biobank study: frequency, distribution by sociodemographic factors, and general health, happiness, and social participation outcomes. J Cataract Refract Surg. 2015;41:2466-7.

25. Hashemi H, Khabazkhoob M, Pakzad R, Yekta A, Nojomi M, Nabovati P The characteristics of excimer laser refractive surgery candidates. Eyes Contact Lens. 2018;44 (Suppl 1):S158-62.

26. Cárdenas T, Machado E, Guerra M. Cirugía refractiva corneal. En: Ríos M, Fernández L, Hernández JR, Ramos M, editores. Oftalmología. Diagnóstico y tratamiento. La Habana: Ciencias Médicas; 2018. p. 89-93.

27. Cárdenas T, Ravelo W, Capote A, Pérez EC, Cuan Y, Hernández I. Poder corneal postcirugía fotoablativa en miopes. Sistema Scheimpflug topógrafo Pentacam vs método de Maloney. Rev Cub Oftalmol. 2014;27(1).

28. Pérez EC, Cárdenas T, Hormigó I, Alarcón E, Trujillo K, Santiesteban I. Correlación de los valores queratométricos del Pentacam y el método de Maloney. Rev Cub Oftalmol. 2016;29(3).

29. Viteri E. Uso del topógrafo Pentacam para calcular el poder de la LIO. High Lights of Ohthalmology. 2008;36(3).

30. Savini G, Barboni P, Profazio V, Zanini M, Hoffer KJ. Corneal power measurements with the topographer Pentacam Scheimpflug camera after myopic excimer laser surgery. J Cataract Refract Surg. 2008; 34:809-13.

31. Jain R, Dilraj G, Grewal SPS. Repeatability of corneal parameters with topographer Pentacam after laser in situ keratomileusis. Indian J. Ophthalmol. 2007;55:341-7.

32. Wang L, Spektor T, de Souza RG, Koch DD. Evaluation of total keratometry and its accuracy for intraocular lens power calculation in eyes after corneal refractive surgery. J Cataract Refract Surg. 2019;45:1416-21. 